\title{
Urban Color Characteristics of Cold City Harbin
}

\author{
$\mathrm{Xu} \mathrm{LU}$ \\ Shenyang Jianzhu University \\ School of Architecture and Urban Planning \\ Shenyang, China \\ e-mail: 715489829@qq.com \\ Zhibin WANG \\ Shenyang Jianzhu University \\ School of Architecture and Urban Planning \\ Shenyang, China \\ e-mail: 314823940@qq.com
}

\author{
Han QIN \\ Guangzhou Traffic Planning Research Institute \\ Department of Urban Planning \\ Guangzhou, China \\ e-mail: 382702514@qq.com
}

\author{
Si LIU \\ Shenyang Jianzhu University \\ School of Architecture and Urban Planning \\ Shenyang, China \\ e-mail:930209623@qq.com
}

\begin{abstract}
This paper uses quantitative analysis approach of urban color and the comparative study method, using China Color System National Technical Standards (GB/T15608-1995) and China Building Color Card as a basic tool for recording and analysis of urban color information. This paper researches on landscape color characteristics of cold city Harbin. Taking seasonal characteristics, urban historical context, rapid urbanization as the impact factors, this paper analyzes formation causes of cold city Harbin's urban color. The research results indicate that, the main mass-tone attunes of Harbin city are moderate light yellow and modern warm gray, building facade of chroma and lightness is significantly higher. This color tendency may be due to the geographical environment. These reasons lead building facade to warmer and brighter color in order to rich people's psychological feeling. At the same time, the influence of Russian culture and Orthodox architectural style is also the vital reason for the formation of Harbin urban color characteristics. Today, Harbin is experiencing rapid urbanization; we should control high-rise building and the impact of the new materials of traditional urban color through the urban color planning and urban design to protect the local color feature.
\end{abstract} Harbin

Keywords-urban color; cold cities; rapid urbanization; China

\section{URBAN COLOR OF COLD CITY}

Urban color, in general, refers to the sum of all colors and appearances presented in public spaces of various urban elements [1], consisting of natural color and artificial color [2]. The causes of urban color are complicated; including region and climate, historical context and scientific and technological development [3], and the seasonal factor has a great influence on urban color. The urban environment in different seasons takes on different colors because of changes in sunlight and air flow. The seasonal changes do not only directly change urban natural color, but also affect the appearance of urban artificial color; and in the long run, they affect the urban residents' habit of using colors.

Compared to other regions, the urban color characteristics of severe cold region are more remarkable.
Harbin is a typical cold-region city in China, with four distinctive seasons and the snowfall period from November to next March. The cold and long winter is the most important factor that must be considered in the urban construction and planning for this region and it provides a unique natural color background for the formation of urban color. With the natural and geographic conditions and many other factors, Harbin forms the local architecture style and humanistic environment with distinctive characteristics.

\section{STRATEGY AND METHODS OF SURVEY}

This study adopts the urban color quantitative analysis method, and employs Chinese Building Color Cards based on GB/T18922-2008 Chinese Color System as the basic tool to record and analyze the color data. First, it studies the urban color characteristics of Harbin, and comprehensively analyzes the causes for formation of urban color with seasonable characteristics as the main factor and also other factors considered, such as urban historical context, climate, natural environment and functional partition. In order to study the influence of seasonal factor on the urban color characteristics of Harbin, the survey was conducted in two time nodes - ordinary season and cold season; for the ordinary season, early October, 2014 was selected, and for the cold season, early January, 2015 was selected.

The object of study is the region that can best represent the urban color features of Harbin, which is the structural form of "one axis with multiple points": "One axis" means Dazhi Street Axis running through Harbin (Xuefu Road West Dazhi Street - East Dazhi Street - Yiman Road Nantong Avenue - Dongzhi Road), which is about $11.8 \mathrm{~km}$ long; "multiple points" refer to important urban nodes diverging around the axis, such as Central Avenue, area around Saint Peter's Basilica, Riverbank Park, Gogol Street and Harbin Railway Station and other landmark regions. The field survey mainly pays attention to the color characteristics of street-facing buildings, structures and main facilities and landscape and covered 299 buildings, including 51 historical buildings, 39 road landscapes and facilities; the objects of survey cover various historical periods of Harbin, including 
many kinds of urban function areas, which can reflect the overall urban features and characteristics.

\section{URBAN COLOR CHARACTERISTIC OF HARBIN}

Through drawing scatter diagram based on the urban color data and making an overall evaluation on the urban color features, we can observe that the urban color of Harbin has the color tendency of "warm tone, high brightness and high saturation". The dominant tone of color in urban architecture facade is dominated by modern warm grey (10RP-10Y, C<1) and steady and mild light yellow (10R$10 \mathrm{Y}, 1<\mathrm{C}<3)$ and supplemented by cold grey $(10 \mathrm{G}-10 \mathrm{~PB}$, $\mathrm{C}<1)$, light green $(10 \mathrm{GY}-10 \mathrm{G}, 1<\mathrm{C}<3)$ and light blue (10GB-10B, $1<\mathrm{C}<3$ ), which are dotted to form a harmony of contrast (Figure 1). The saturation and brightness of urban color are both high; the high-brightness colors $(\mathrm{V}>6)$ account for $91.5 \%$, and many colors are repeatedly used, which shows that specific colors are often used regularly in the urban construction, shaping a cultural context heritage of urban color.

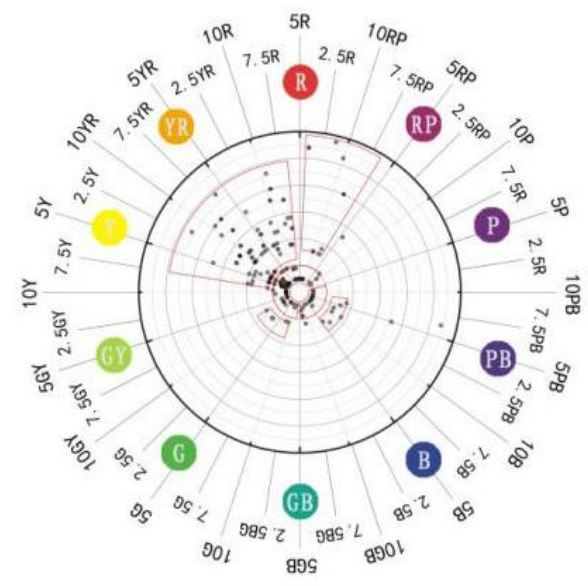

Figure 1. Hue-saturation scatter diagram of dominant color in architecture facade

In cold climate conditions, the materials of building facade in Harbin are mainly paint (56\%) and face brick (39\%) and the same type of bare brick and bare concrete. The representative landscapes are warm red brick wall, deep red roof, light yellow small face brick and cold grey modern face brick. Paint is the most widely used and has the strongest color rendering; apart from the color range of the traditional facade materials, it can also be used to display blue and green systems. Compared to the cities in South China, Harbin has fewer glass curtain walls, and the exterior wall glass is not limited to blue. There are not only such traditional glass colors as grass green and red brown, but also such modern glass curtain wall colors as blue and bluish violet.

\section{THE IMPACT OF COLD CLIMATE ON DECORATION COLOR}

\section{A. The Impact of Cold Climate on Nature Color}

Natural color refers to the sum of colors of natural elements in cities, such as soil and stone, grassland, trees, waters and sky [4]. In severe cold region, the composition of natural color in urban color in long winter has obvious change, which is mainly shown in that the hue distribution area of natural color becomes narrow and that the color tendency changes obviously. The plant communities in winter go to sleep, so the green colors and yellow colors reduce while the blue sky, reddish yellow soil and white snow constitute the main background. The color of sky becomes high-saturation blue from low-saturation light blue in ordinary season, and the soft sense of color becomes colder (Figure 2).
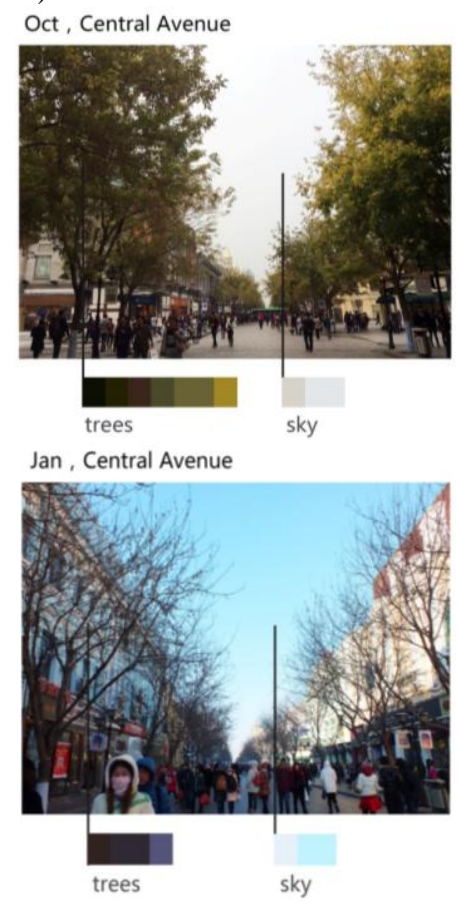

Figure 2. Contrast analysis of natural color in different season

In winter, green in natural colors disappears for a long time, making the urban tone colder, giving people a feeling of desolation and making people feel depressed for a long time [5]. In order to make up for people's demands for urban environmental green, the cities in cold regions usually applies the green elements scattered throughout street scenes, such as light green wall, grass green roof and sculpture sketch.

\section{B. The Impact of Cold Climate on Building Color}

The cold weather mainly affects the tone of building exterior facade in Harbin through light angle and light duration. In Harbin, in winter, the solar altitude is low, so the large-area shadow area weakens the color effect of building facade. As a result, the building color is more inclined to high brightness and high saturation of strong 
color rendering. China has a vast territory and the latitudinal difference between the South and the North is about 50 degrees; the difference between shadow length rates at noon under the same daylight standard is 3-4 times [6], and in winter, the difference is even larger. In winter, some buildings in Harbin are in the shadow in most of the time during the daytime. According to the analysis on the street scene from different directions at the same time, it can be found that the shadow area has a smaller influence on the color of the southern side of east-west streets while it has a greater influence on that of the northern side. The color rendering changes along with the light direction; at noon, the color rendering is the closest to that in ordinary season; both sides of the north-south streets are affected by the building shadow, and the overall tone is darker compared to the color rendering in ordinary season.

Short light duration is another characteristic of coldregion cities, and it determines that the building colors are more inclined to be warm. In such cities, the daytime in summer is the longest, reaching 18-19 hours, but in winter, it is only around 8 hours. On the one hand, at dusk and dawn, the solar angle is relatively low and the sunlight with a strong transmission can reach the ground only after passing through the deep atmospheric layer. The long-wavelength red light can more easily pass through the atmospheric layer and beat down on the building facade than the shortwavelength violet, indigo and blue lights with a weak transmission, so the light yellow high-rise building facades looks orange and red at dusk and dawn. In winter, the daytime becomes short, so the influence of solar refracted light on the color of building facades appears before 10:00am and after 2:00pm. Compared to the ordinary season, the dusk and dawn accounts for a larger proportion in the daytime, so the overall tone of buildings during the daytime appears warmer. On the other hand, sunshine is of great significance to people, and it is indispensable to both physical and mental health. And in the cold-region cities with short solar irradiation time, warm tone is more needed. So the off-white colors $(8.5<\mathrm{V}<9.5, \mathrm{C}<1)$ [7] with higher light reflectivity are more applied to meet people's psychological need, because they can disperse the negative mentality of the residents from cold and give them a healthier psychological suggestion.

\section{The Impact of Cold Climate on Decoration Color}

Decoration color, as a smaller-scale color, is the closest to the feeling of human body and has a more direct influence on people, and it can make the finishing point through the harmonization with the main color of building facade. Cold climate also affects the decoration colors with a short replacement period. In most of the time in winter, the lower part of buildings along the streets is in the shadow, and the building facade appears to be a low-brightness cold tone. Therefore, in Harbin, high- saturation warm colors are often used on such places as the roofs, commercial signboards and wall decorations of buildings to make up and adjust (Figure $3)$.
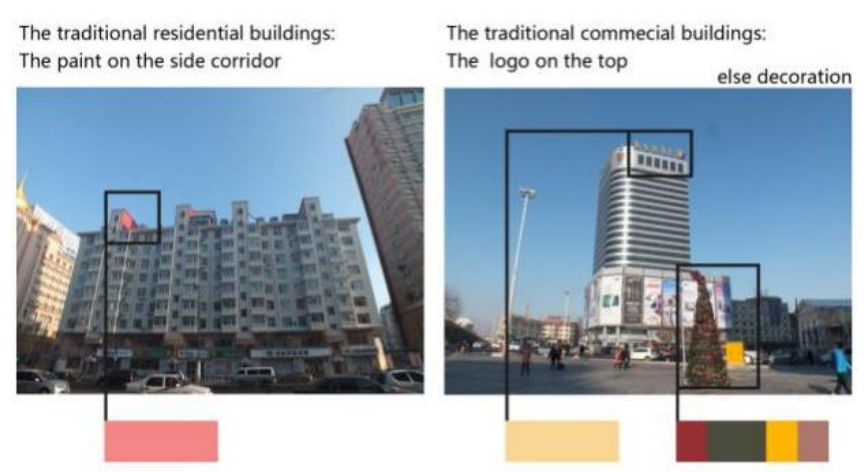

The traditional residential buildings: Dark inclined housetop

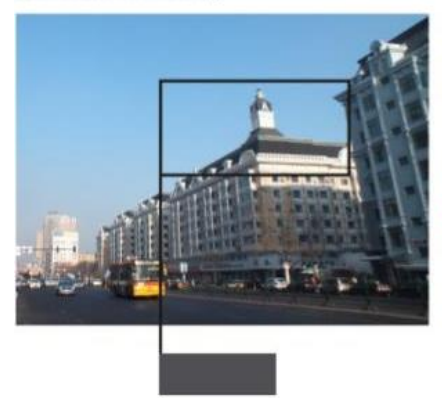

The traditional commecial buildings: The signs of underlying shops

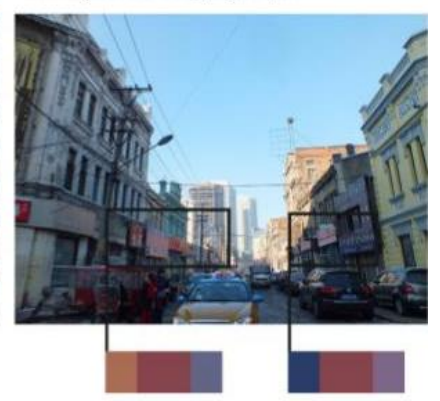

Figure 3. Analysis of decoration color on architecture

In long winter, the color effect of the lower part of buildings is affected because of the shadow, but the roof still can accept the direct sunlight, so high- saturation deep blue, green and crimson colors are often used to decorate the roofs. These colors can easily absorb the sunlight and heat and animate the color atmosphere. And similar decoration techniques can also be found on protruded side walls on the top of the residential buildings.

High-saturation warm-color decoration boards or signs are usually used on the top of the modern commercial buildings so as to make the whole building more vivid, such as the golden yellow nameplate on the top of the commercial buildings. The street-facing signboards of the commercial buildings also usually adopt high-saturation warm colors with a strong undulating feeling, such as the signboards of red background with white words or deep blue background with red words. Moreover, the warm color combinations are often found in the landscape sketches and public facilities in front of the commercial buildings, such as the decoration hanging on the plants, temporary advertising board and street safety facilities. They together create a commercial atmosphere that can animate the customers' mental feelings and attract people.

\section{The Impact of Cold Climate on Urban Night Scene Color}

Winter in Harbin is long and dull. It fails into night at 15:30-16:00, and the visible time of urban color under the sunlight is shorter, so the illumination of artificial light is urgently needed to meet people's visual demand and psychological need for urban color. Harbin creates a high- 
brightness and rich-color artificial lighting environment. The colorful lights adjust the overall dull color of the city in winter, and also become an important component of the urban color landscape characteristics.

The night scene colors in Harbin are very rich. The general buildings and structures are decorated with yellow or orange warm-color lights. The golden yellow street lights are frequently used and they are in the same style, uniform and harmonious. Red, white and green lights are dotted in such commercial areas as Central Street and Gogol Street. So, the street takes on a golden yellow street scene with red and green dots, and it has high color brightness, making people feel warm and cozy. Besides, in winter, Harbin makes use of ice sculptures and snow sculptures and lights to form unique ice-snow night scenes. On the street, colorful ice sculptures and snow sculptures projected by various colors, like red, blue and green, can be seen; and the orange or yellow street lights in the evening, and the high-saturation ice lights with rich hues enrich the night urban color (Figure 4).

the whole night scene color
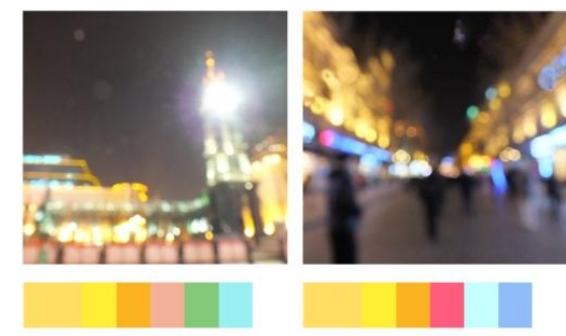

the special night scene color the night scene color
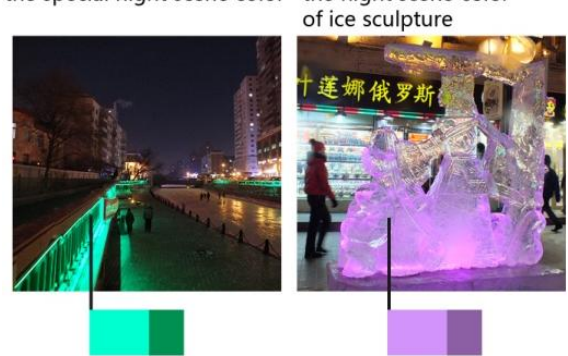

Figure 4. Analysis of urban night scene color

\section{CONCLUSION}

Based on the application and improvement of the domestic quantitative analysis method on the urban color, and in combination with the qualitative analysis on coldregion cities, this study thinks the dominant tone of Harbin is dominated by steady and mild light yellow and modern warm grey. Compared to other cities in China, the saturation and brightness of building facade are higher; the tone is more inclined to be warm; the application proportion of building paint is higher, and it has distinctive features. The cause of this color tendency may be the cold-region geographical environment. Harbin has four distinctive seasons, long and cod winter and short daytime; the background color of the city is colder and deeper and it lacks green background. As a result, the colors of the building facade are warmer and brighter to enrich people's mental feelings. At the same time, the Russian culture and influence of architectural style of Orthodox are also important reasons for the urban color features of Harbin.

\section{REFERENCES}

[1] Lu Xu, Yin Jie, Ding Yu, Chen Peng. Urban color investigation and quantitative analysis: taking Shenzhen shennan avenue as an example. Urban Planning, 2010, 34(12), pp.88-92.

[2] Cheng Quanguo, Lv Xiaoying. Shenyang urban color planning and design. Journal of shenyang agricultural university (social science edition), $2006-09,8(3)$, pp.545-547.

[3] Wu Songtao, Lu Ming, Guo Rong. The research on urban color planning in cold city. Low Temperature Architecture Technology, 2001(3), pp.17-18+26.

[4] He Ying. The influence analysis of climate factors on the urban color . Journal of Tianjin institute of urban construction, 18(2), pp.87-93.

[5] Zhang Min. Do a good transformation of urban color in cold city, shaping the new image of city. engineering technology, 2014(19), pp. 138 .

[6] Harbin urban planning design and research institution, Harbin university of technology, school of architecture. Feasibility study of performing the national standard of the sun in Harbin. [EB/OL]. [2005-12].http://www.upp.cn/upp_web/e/e08/e08_006.htm

[7] Junichi Nomura, translated by Zhang Lei. Color psychology. Haikou: Nanhai Publishing Company, 2014. 